\title{
The investigation on the ideal spot weld numerical model in resistance welding
}

\author{
Zygmunt Mikno ${ }^{1} \cdot$ Bogusław Grzesik ${ }^{2} \cdot$ Mariusz Stępień $^{2}$
}

Received: 21 April 2020 / Accepted: 16 September 2020 / Published online: 6 October 2020

(C) The Author(s) 2020

\begin{abstract}
The paper presents investigation on the ideal spot weld numerical model. The weld discussed in the paper was made by the resistance spot welding of two overlapping steel sheets. The ideal weld contained three parts, i.e. two welded steel sheets and an intermediate component (connector) made of the same material. The connector was placed between the sheets, assembled mechanically and fixed. A numerical model of the ideal weld enables the elimination of all welding imperfections, including, among other things, an indent left by the electrode as well as stresses and deformations of materials present in the actual welded joint. The ideal weld was intentionally not subjected to the thermal cycle. As a result, the heat-affected zone and the molten nugget were eliminated from the model (welding area). Consequently, the entire tested (analysed) weld specimen only had the properties of the base material. The analysis presented in the paper is based on 3D FEM numerical modelling and experimental validation. The numerical model of the ideal weld (nugget surface) was investigated in relation to various shapes of the nugget (e.g. circular, square and rectangular) as well as in relation to different dimensions. The research also involved the performance of a comparative analysis including various welding conditions. The analysis was carried out to determine the highest possible value of shear force generated during a static tensile test. The results of the numerical tests were compared with the results of selected laboratory tests.
\end{abstract}

Keywords FEM $\cdot$ Resistance spot welding $\cdot$ Ideal resistance weld $\cdot$ Ideal spot weld numerical model in resistance welding

\section{Introduction}

Results of scientific and engineering investigations reported in publications, not only those related to resistance welding, are usually focused on modifications of technological processes aimed to improve both the process and the quality of finished products. In terms of resistance welding, goals are usually joint-related improvements achieved through the reduction of welding imperfections, increased process repeatability and/or the higher strength of welded joints [1-3]. However, reported investigations related to the strength of joints usually

Zygmunt Mikno

zygmunt.mikno@is.gliwice.pl

1 Department of Resistance and Friction Welding and Environmental Engineering, Welding, Research Network, Institute of Welding, Gliwice, Poland

2 Faculty of Electrical Engineering, Silesian University of Technology, Gliwice, Poland lack indications concerning a theoretical upper ultimate value of joint strength [4].

Information concerning welded joints made using resistance spot welding state that such welds are subjected to shearing. Related recommendations suggest avoiding the use of welds affected by tension or torsion [2]. For this reason, the primary analytical criterion adopted in this paper was the shear strength of the weld. Other strength-related criteria such as cross-sectional tensile strength, torsional strength or peel strength were not taken into consideration when assessing the quality of welds. In addition, the quality-related analysis presented in this article did not include a depth to which electrodes penetrated the material subjected to welding ('indent').

In terms of the ideal weld, the analysis is concerned with the most appropriate shape (surface) of the weld as regards the effect of the weld nugget shape on the strength of the welded joint. In the analysis, the thermal cycle, having a significant, yet disadvantageous effect on structural changes not only in the weld material but also in the entire welding area (particularly in the heat-affected zone), was not taken into consideration. The lack of the effect of the thermal cycle translates into 


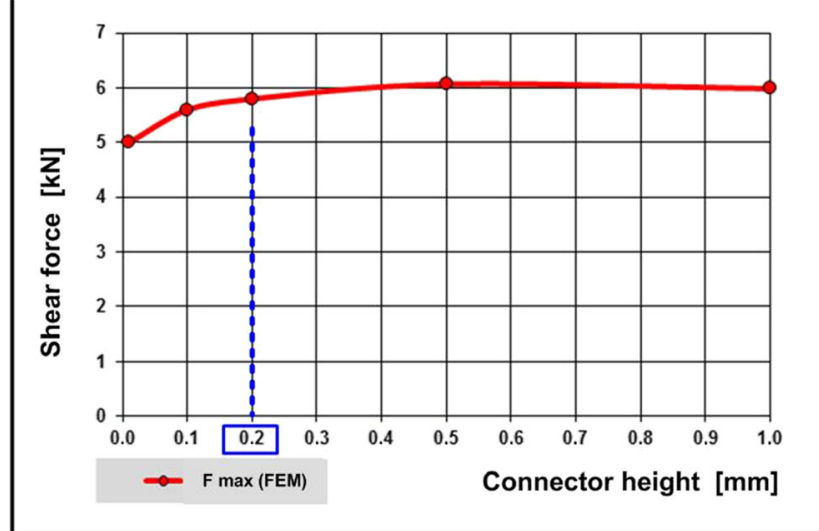

Fig. 1 Effect of the connector height on the value of shear force in a static tensile test (FEM calculations)

the lack of division into the base material, weld nugget and the HAZ. For this reason, the analysis only involved the size and the shape of the weld nugget surface in the plane perpendicular to the electrodes, i.e. the plane in which elements are welded. The analysis did not take into consideration the height and the shape of the weld nugget in the direction of the electrode axis. In view of the aforementioned assumptions, including the lack of a thermal cycle, the numerical model did not include the aforesaid area.

The results presented in the paper constitute a part of wider analysis focused on the proper quality of the weld. The subject of the research was the ideal weld, where the shape and the size of the weld nugget were also affected by force, its value and course. Electrode force and/or movement can be controlled using an electromechanical system. The tests performed and discussed in this paper were based on the classical, i.e. pneumatic electrode force system.

\section{The ideal weld}

The analysis of reference publications involved the usage of the term of 'the ideal weld', yet it primarily referred to the ideally made welded joint. The appearance of the weld was analysed in publication [4], whereas the analysis constituted visual assessment. The analysis involved the comparison and the assessment of welded joints in relation to the depth of the indent left by the electrode in the base material and the diameter of the indent as well as the presence of cracks (if any) and expulsion. Measurements were performed using a camera in a manner enabling the obtainment of quantitative results.

The term of the ideal weld contained in work [5] also referred to the weld made ideally in physical terms. The ideal weld is perceived as a joint free from various welding imperfections. The authors mentioned the presence of numerous obstacles and factors which affect the obtainment of the ideal welded joint yet which, at the same time, are difficult to identify.

In available reference publications, the notion of the ideal weld was attributed to welded joints obtained in technological welding tests, i.e. where, as a result of the flow of current, the material being welded was subjected to a thermal cycle.
Table 1 Parameters of FEM calculations

\begin{tabular}{lllll}
\hline & Initial force & Time of current flow & Final force & \\
\hline Calculation step & 1 & 1 & 1 & $\mathrm{~ms}$ \\
Recording of data & 5 & 5 & 5 & Steps \\
Welding paramaters & & & & \\
Variant number & Current & Time & Force & Final force \\
& $\mathrm{kA}$ & $\mathrm{ms}$ & $\mathrm{kN}$ & $\mathrm{ms}$ \\
M1-M9 & 0.1 & 1 & 0.1 & 500 \\
M10 (high parameters) & 10 & 160 & 3.0 & 500 \\
M11 (low parameters) & 7 & 400 & 1.5 & \\
Convergence of calculations (covergence control) & & & \\
& Degree of convergence & & \\
Electric model & $1.00 \mathrm{E}-5$ & & \\
Thermal model & $1.00 \mathrm{E}-5$ & & & \\
Mechanical model & $1.00 \mathrm{E}-5$ & & & \\
Heat losses to the environment & & & \\
Ambient (air) temperature & 20 & & \\
Heat transfer coefficient & 300 & F0 & & \\
Electrode type & DC $1 \mathrm{kHz}$ & & \\
Welding current type & Pneumatic & & \\
Force system & & & \\
\hline
\end{tabular}


However, the publications did not contain information concerning the ideal weld as presented in this article, i.e. the analysis of the weld in terms of shear strength, deliberately ignoring the thermal cycle.

Numerous researchers use numerical modelling for the analysis of resistance welding process, detailed analysis of processes taking place during welding and optimization of the welding process [6-11]. Many authors attempt to achieve the optimal, i.e. most favourable welding parameters and, consequently, to obtain the perfect welded joint [12-15].

A few works are focused on the determination of weld nugget parameters $[4,5,16]$. The resistance welding process depends on numerous variables including welding parameters (hard and soft) as well as the size and the shape of indents left by electrodes. The indents depend on welding cycle parameters and the shape of working parts of electrodes.

The optimization of the welding process requires the acquisition of knowledge concerning the strength parameters of the ideal joint obtained using the resistance welding process. When doing so, it is important to answer the essential question about how research related to the optimization of the welding technology can bring the ideal weld (or ideal joint) closer [16].

\section{General assumptions}

The results reported in the paper are based on the analysis of several variants of the ideal weld. The calculations and experiments have been carried out for the steel of $1.5 \mathrm{~mm}$ thick steel grade DX53 [17]. The analysis involved the following:

- Weld nugget shapes, i.e. circular, square and rectangular,

- Weld areas,

- Double systems of welds (serial, parallel) in relation to the direction of shear force.

The research-related calculations were performed using SORPAS® software [18]. The computational model included an additional element, i.e. the so-called connector. The nonzero thickness of the connector resulted from the lacking possibility of directly "gluing" the elements of the sheets in the computational model (after previously assuming the shapes and dimensions of the ideal, i.e. circular, weld nugget). Exceptions included variants of non-overlap joints (M9) and a variant designated as the "gluing" of sheets (M2), in relation to which the thickness of the connector amounted to zero.

The analysis was performed in relation to various thicknesses of the connector restricted within the range of 0.01 to $1.0 \mathrm{~mm}$ (c.f. Fig. 1). To ensure the highest possible accuracy of calculations (FEM) and because of the fact that the connector applied for the calculations did not actually exist, the numerical calculations were performed in relation to the lowest possible height of the connector amounting to $0.2 \mathrm{~mm}$, i.e. the

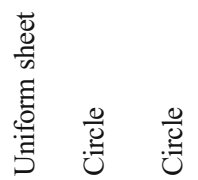

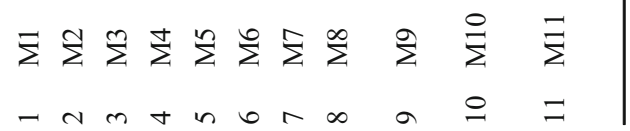


Fig. 2 Analysed shapes and dimensions of the weld nugget

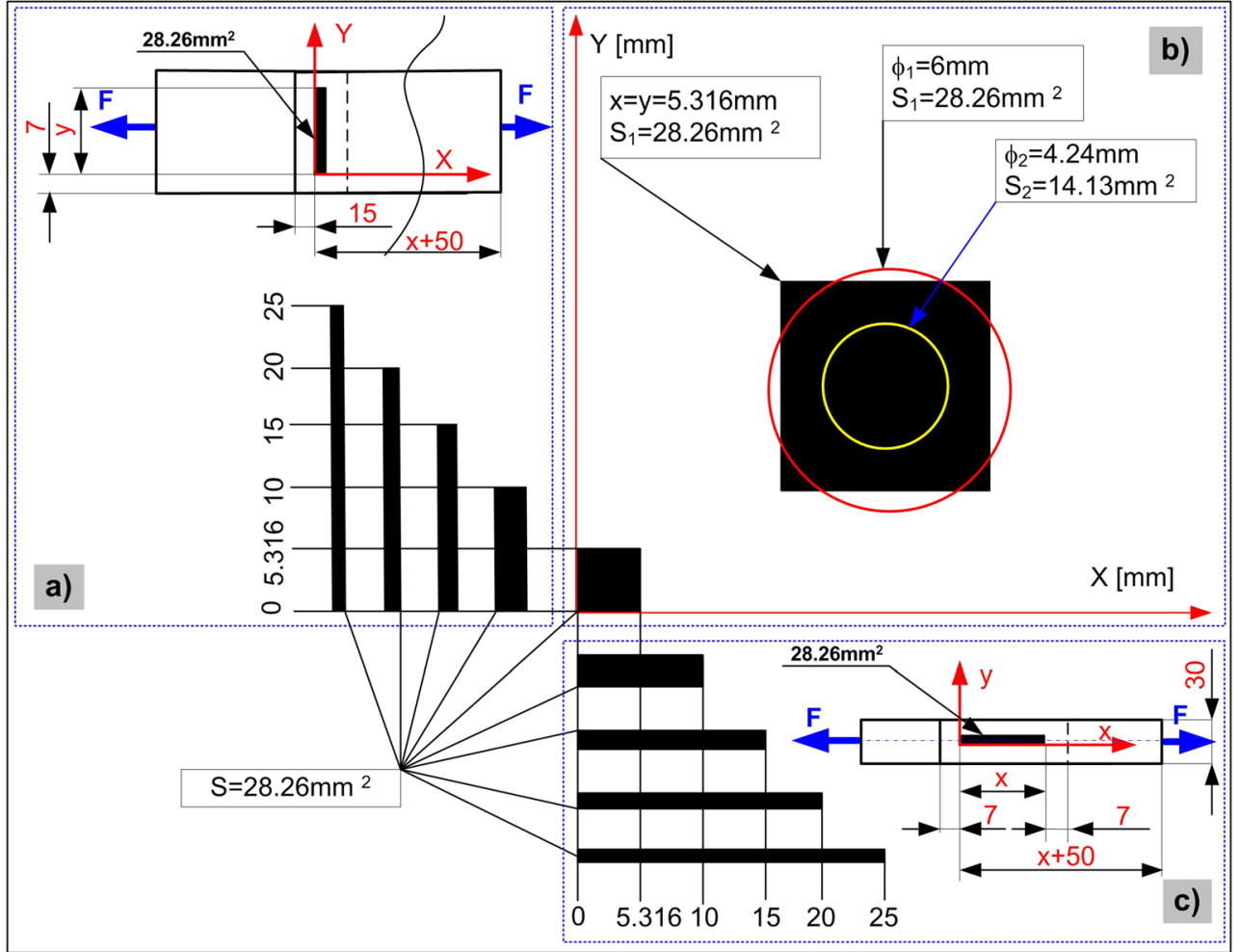

value recognised as sufficient for accurate numerical modelling (SORPAS®) [18]. Higher values of the connector height did not significantly increase the strength of the weld, whereas the reduction of the connector height decreased the strength of the weld and, consequently, reduced the accuracy of calculated results (Fig. 1). In addition, the adopted connector height $(0.2 \mathrm{~mm})$ was not connected with the introduction of an artificial notch which could initiate cracks, particularly at the beginning of a shear test (resulting from the sharp edges of computational model geometry). The above-presented model (as indicated by related calculation results) enabled the accurate and complete analysis of phenomena occurring during shearing, e.g. elongation.

The ideal weld (sheets and the intermediate element, i.e. the connector), in nine analysed variants (M1 to M9) was modelled as one mechanically inseparable part. The material of the ideal weld was the same (homogeneous) and the whole part was not subjected to any thermal cycle. The properties of the entire joint were the same as those of the base material (sheet). The foregoing resulted from the fact that the joint was not exposed to the negative effect of the thermal cycle. The FEM calculations were performed in relation to the minimum necessary value of current $(0.1$ $\mathrm{kA}$ ) and a current flow time of $1 \mathrm{~ms}$, required by the SORPAS® software for calculations including heating and shear tests [18]. However, the above-presented current parameters did not significantly affect the temperature of the material, and, as a result, the temperaturerelated (metallurgical) properties of the material.

The remaining model parameters were the following:

- Sheet (specimen) width of $30 \mathrm{~mm}$ - in relation to a single joint (one weld) and $55 \mathrm{~mm}$ in relation to double joints in
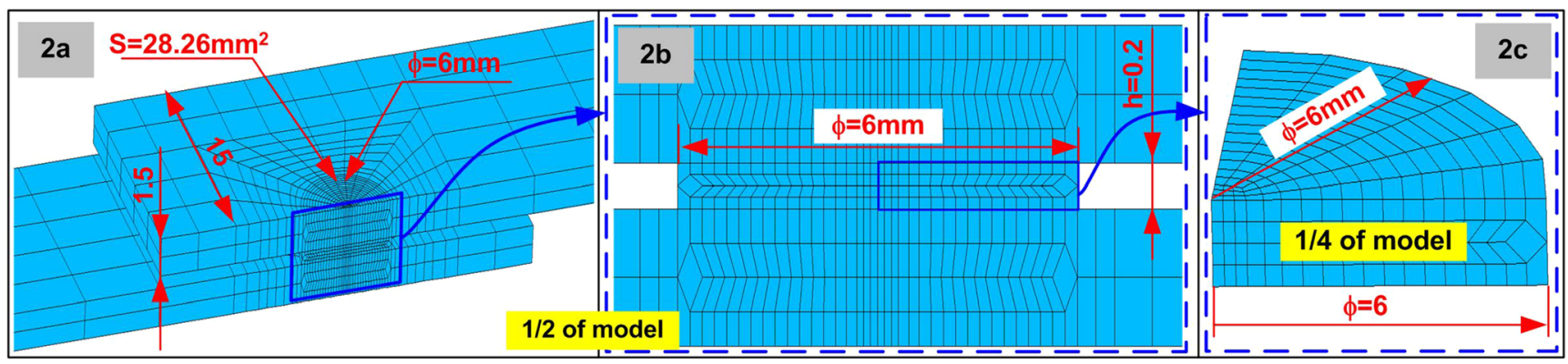

Fig. 3 Shape and dimensions of the specimen (variant M1) 


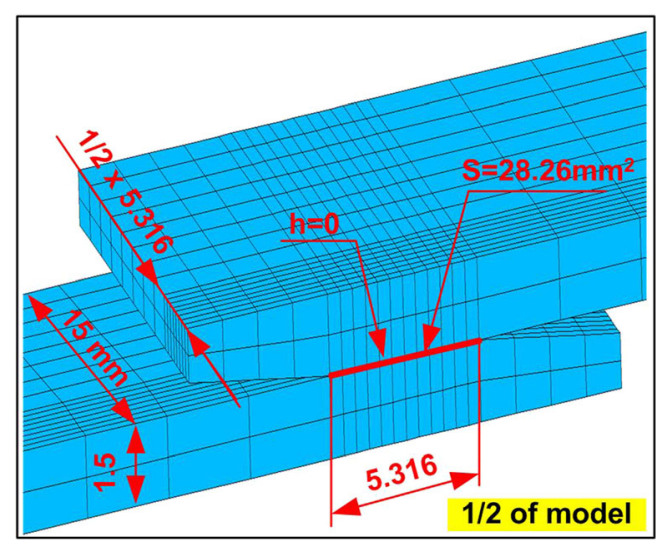

Fig. 4 Shape and dimensions of the specimen (variant M2)

the parallel system of welds in relation to the direction of the shear force effect,

- Sheet length of $70 \mathrm{~mm}$ - in relation to a single joint (one weld) and $95 \mathrm{~mm}$ in relation to double joints in the serial system in relation to the direction of the shear force effect.

The numerical calculations of the first nine variants (M1M9) were performed to determine shear strength in relation to the so-called ideal weld. Variants M10 and M11 referred to the strength of the weld in relation to the computational welding process, in relation to high and low welding parameters (c.f. Table 2) respectively. The shear test followed the welding process-related calculations (FEM), where welding parameters affected the diameter and the height of the weld nugget and also influenced the distribution of temperature in the welding area. The shear test constituted the second (conjugated with the first) stage of numerical calculations performed using the SORPAS ${ }^{\circledR}$ software programme [18]. The parameters used in the calculations are presented in Table 1.

\section{Assumptions for comparative analysis}

The comparative FEM analysis of ideal weld parameters was performed in relation to various assumptions including the shape and the dimensions of the weld nugget and the height of the connector (h). The analysed variants of (FEM) numerical calculations designated using the letter $M$ (as in Computational $M o d e l$ ) and a related number are presented in Table 2. To verify the FEM-based calculations, the analysed variants were subjected to technological welding tests; the above-named variants were designated using the letter $E$ (as in Experiment).

The $x$-coordinate represents the weld nugget dimension in the parallel direction, whereas the $y$-coordinate represents the weld nugget dimension in the perpendicular direction in relation to the shear force effect respectively.

\section{Description of numerical models}

Different shapes of the weld nugget and the specimens in relation to the selected variants of the computational model along with the mesh and characteristic dimensions are presented in Figs. 2, 3, 4, 5, 6, 7, 8, and 9. The last figure presents the direction of shear force application in relation to the elements being welded. The analysis involved the circular and the rectangular shape of the weld nugget (connector). The schematic diagrams of the analysed shapes of the connector along with its dimensions in relation to:

- Circular weld nugget having nominal diameter $\phi_{1}=$ $6.0 \mathrm{~mm}\left(S_{1}=28.26 \mathrm{~mm}^{2}\right)$ in relation to 1.5 -mm-thick sheets (Fig. 2b),

- Circular weld nugget having half the area $S_{2}=14.13 \mathrm{~mm}^{2}$ $\left(1 / 2 \times 28.26 \mathrm{~mm}^{2}\right)$, i.e. diameter $\phi_{2}=4.24 \mathrm{~mm}$,

- Square weld nugget (Fig. 2b) and a rectangular weld nugget (Fig. 2a/c)

are presented in Fig. 2.

Figures 3, 4, 5, 6, 7, and 8 show the geometric details of the numerical model (in particular, the shape of the specimens), in relation to which the numerical calculations concerning shear force were performed.

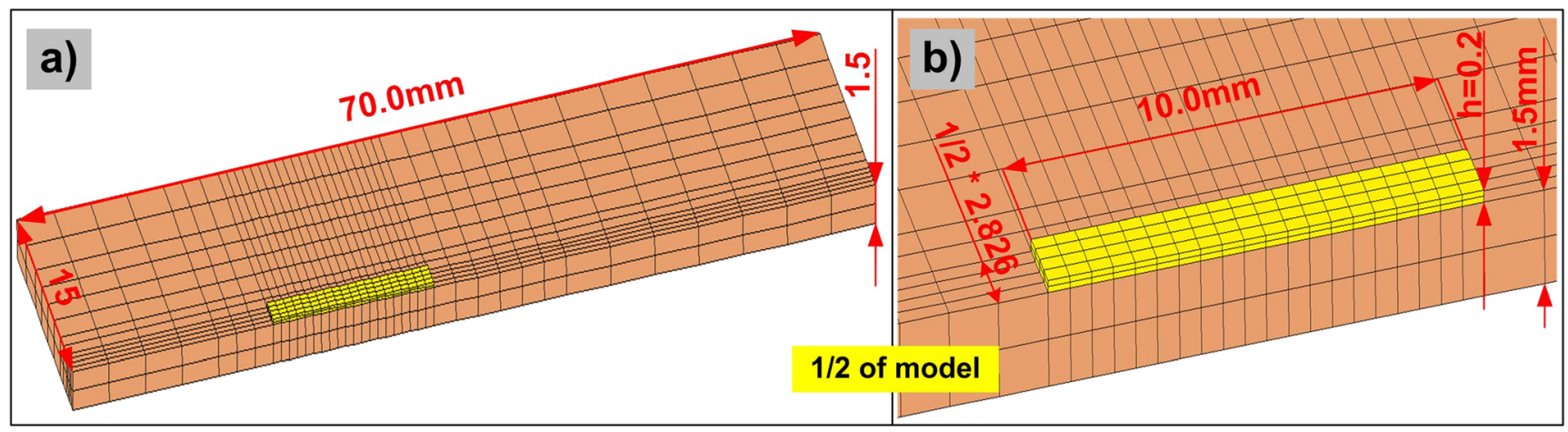

Fig. 5 Shape and dimensions of the specimen (variant M5) 


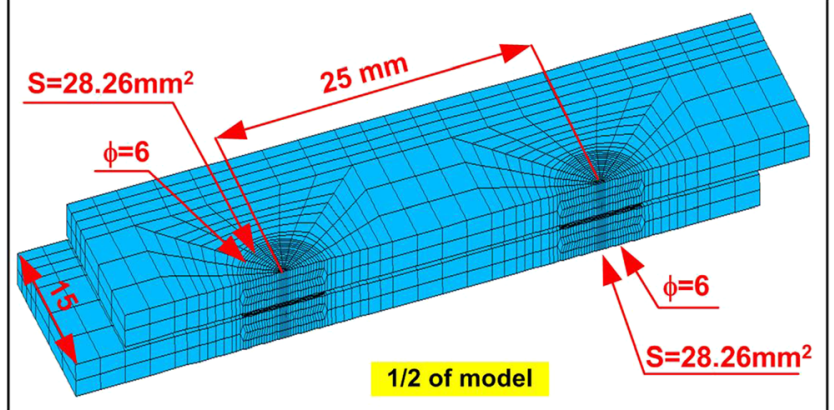

Fig. 6 Shape and dimensions of the specimen (variant M6)

Figure 3-variant M1, circular weld nugget, the diameter and the height of the connector $\phi=6 \mathrm{~mm}$ and $h=0.2 \mathrm{~mm}$ respectively

Figure 4-variant M2, square weld nugget $x=y=$ $5.316 \mathrm{~mm}$ ("gluing" of sheets)

Figure 5-variant M5, rectangular weld nugget, $(x=$ $10 \mathrm{~mm}, y=2.826 \mathrm{~mm}$ )

Figure 6-variant M6, two circular weld nuggets in the system of serial welds $\left(2 \times \phi_{\text {nugget }}=6.0 \mathrm{~mm}\right)$

Figure 7-variant M8, two circular weld nuggets in the system of parallel welds $\left(2 \times \phi_{\text {nugget }}=4.24 \mathrm{~mm}\right)$

Figure 8-variant $\mathrm{M} 9$, non-overlap (butt) joint, $(S=$ $28.26 \mathrm{~mm}^{2}$ )

The model used in the numerical calculations concerning the welding process and the tension (shearing) of the specimen is shown in Fig. 9. The calculations aimed to obtain a welded joint characterized by specific parameters, i.e. the weld nugget diameter, and to determine shear strength in relation to the obtained joint (weld nugget size).

\section{Overview of results}

Representative results of the numerical analysis were shear force and shear strength being correlations of various parameters. Selected results of numerical calculations are presented as follows:

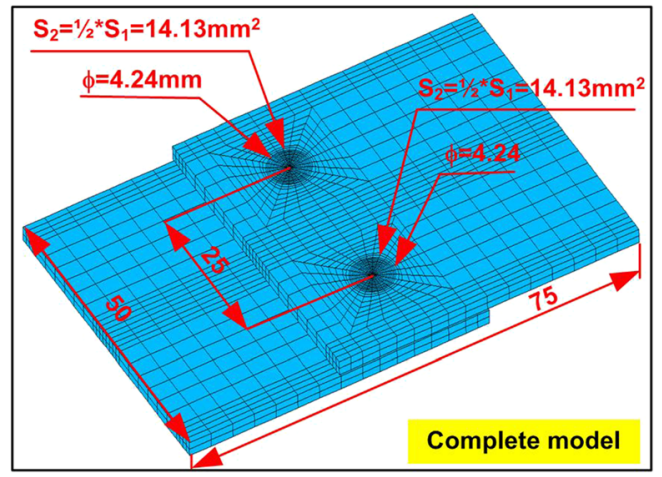

Fig. 7 Shape and dimensions of the specimen (variant M8)

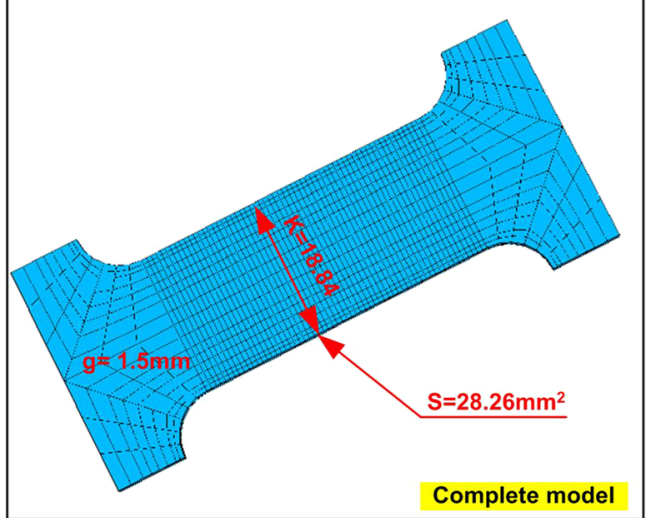

Fig. 8 Shape and dimensions of the specimen (variant M9)

- Shear force $\left(F_{\mathrm{S}}\right)$ in the static tensile test in relation to eleven analysed variants, i.e. various configurations, shapes and dimensions of the welded joint (Fig. 10);

- Relative percentage shear force for variants M2 through M11 in relation to reference variant M1 (Fig. 11);

- Shear force in relation to high $[\mathrm{H}]$ and low [L] parameters in the function of weld nugget diameter (Fig. 12);

- Shear force and shear strength $\left(R_{\mathrm{t}}\right)$ in the function of weld nugget diameter in relation to the reference weld (variant M1) (Fig. 13).

The analysed variants related to the nominal dimensions of the weld nugget area amounting to $28.26 \mathrm{~mm}^{2}$ are presented in Table 2. In addition, in relation to variants M10 and M11, welding parameters are presented in Table 2. Various values of the weld nugget diameter $(2.5-6.0 \mathrm{~mm})$ and, consequently, various values of shear force (Fig. 12) were obtained as a result of various welding times set in the computational model in relation to variant $\mathrm{M} 10$ and M11. In terms of the results presented in Fig. 13 (variant M1), shear force was determined in numerical calculations performed also in relation to a different weld nugget (connector) diameter, in the numerical model, within the range of 2 to $6 \mathrm{~mm}$.

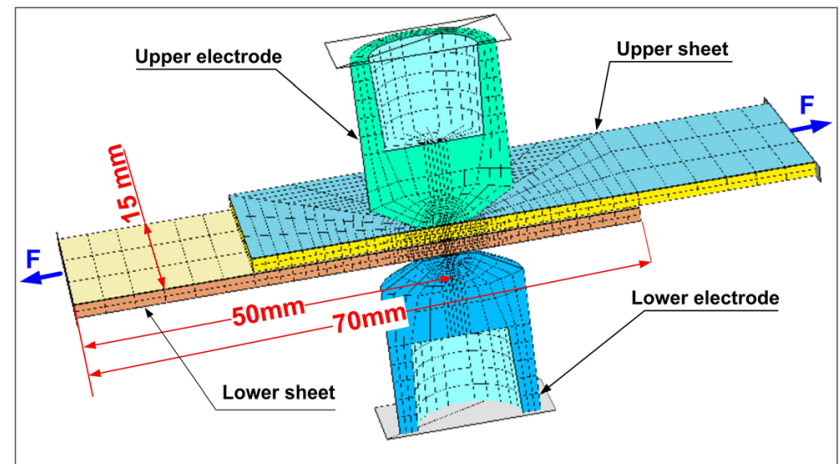

Fig. 9 Computational model (3D) in relation to the numerical welding process and shear force in the static tensile test (variant M10 and M11) 
Fig. 10 Shear force in the static tensile test in relation to 11 analysed variants (FEM calculations-SORPAS $($ )

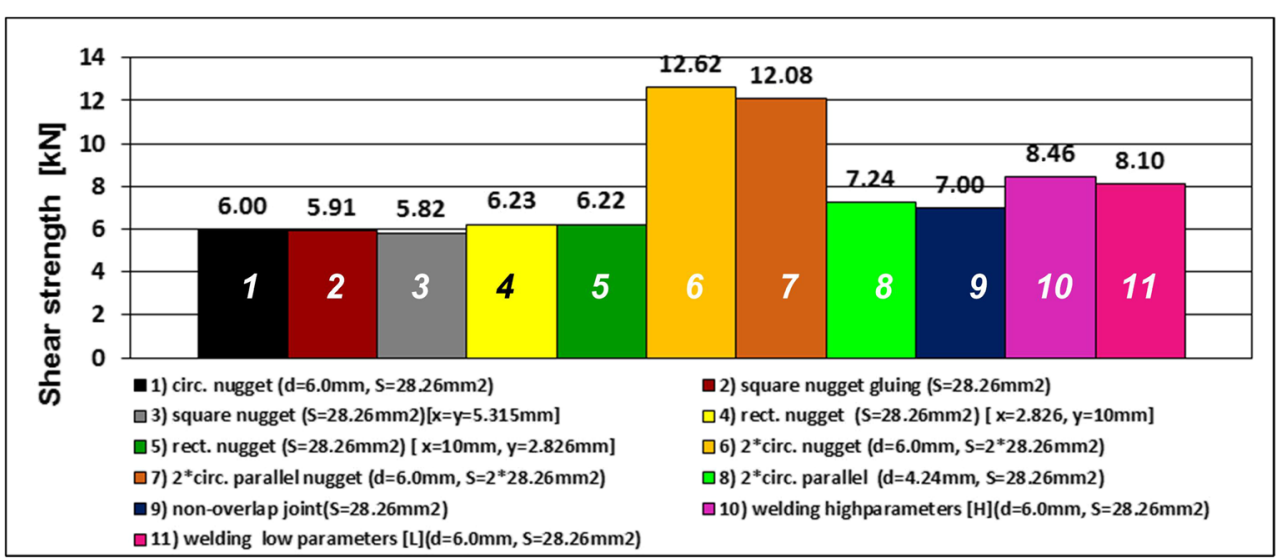

\section{Results of comparative analysis}

\subsection{Analysis in relation to various weld shapes}

Figure 10 presents the shear force values obtained in the static tensile strength tests involving the analysed 11 variants of the ideal weld. The variant selected for reference purposes was designated as M1 (Table 2, line 1), where the weld nugget diameter amounted to $6.0 \mathrm{~mm}$ and its area was $S=$ $28.26 \mathrm{~mm}^{2}$. The sheets were joined using a connector having a height of $0.2 \mathrm{~mm}$. The additional element, i.e. the connector (area), represented the weld nugget. The analysis involved a weld nugget diameter of $6.0 \mathrm{~mm}$ - calculated by (1) and based on the dependence recommended in relation to the welding of 1.5-mm-thick sheets (c.f. [2]):

$d=5 \sqrt{g}$

Shear force in relation to the above-named weld was determined in numerical calculations and amounted to $F_{\mathrm{S}}=6.0 \mathrm{kN}$ (variant M1). Variant M1 was used as a reference when determining relative percentage differences of shear force in relation to other variants subjected to analysis and presented in Fig. 11.
The highest shear force $(7.24 \mathrm{kN})$ was obtained in variant M8 (Table 2, line 8). In the above-named case, the shear force was by approximately $21 \%$ higher than that related to reference variant M1. In terms of variant M8, the test involved the determination of shear strength in relation to half the area of a single welded joint. However, the test involved the making of two welds, each having an area of $S=14.13 \mathrm{~mm}^{2}$. The total area of both welds was the same as the nominal weld nugget area in the reference variant (M1, $S=28.26 \mathrm{~mm}^{2}$ ). The abovenamed welds were made in the parallel arrangement. It turned out that the shear strength in relation to the two welds having a smaller area individually but the total area being equal to that of the reference weld area (variant M1) was higher by more than $20 \%$.

Assuming the highest value of the shear strength in the static tensile test as the primary criterion, the most favourable variants were M8 and M6. Variant M8 revealed an increase in shear strength in relation to two welds having a smaller weld nugget area, yet the total area was equal to the reference weld area (variant M1). The obtained result implied that the adopted criterion (1) of the weld nugget diameter in relation to the sheet thickness was not the most favourable one. Bearing in mind the highest shear strength, it would be necessary to verify the selection criterion of the weld nugget diameter in relation to the
Fig. 11 Relative (percentage) shear strength in the static tensile test in relation to reference variant M1 (FEM calculationsSORPAS $(\mathbb{)})$

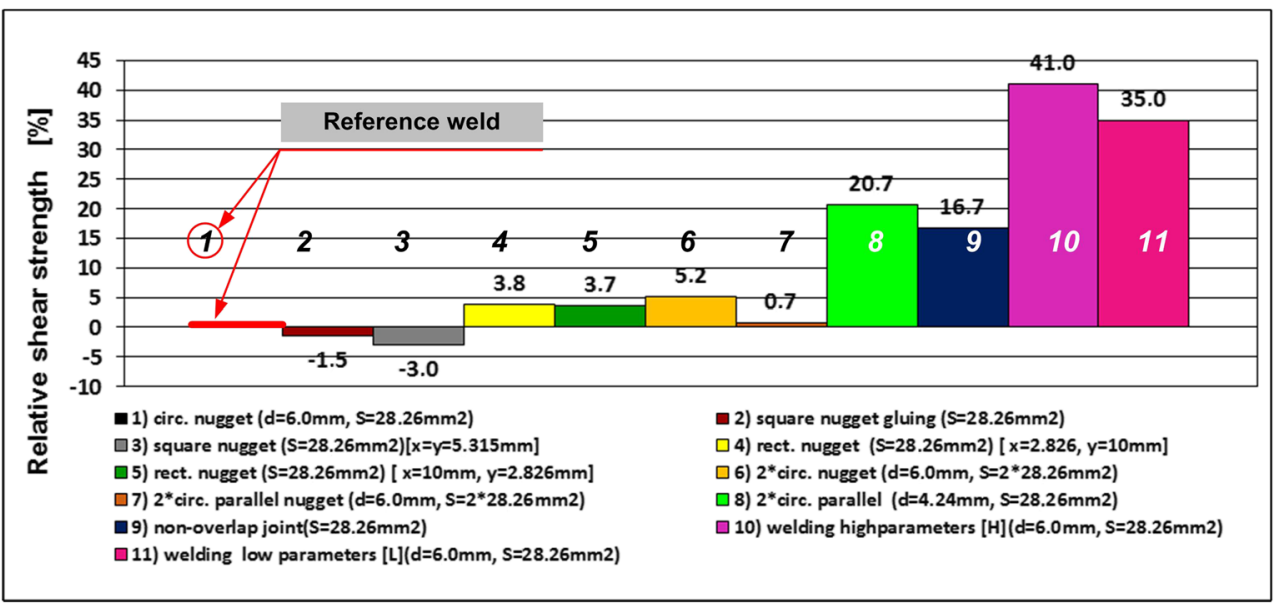


sheet thickness referred to in publications [2, 19]. In terms of the above-presented aspect, the most favourable are recommendations provided by the AWS (American Welding Society) [20], i.e. specified in the US standards (2), enabling the obtainment of higher shear strength.

$d=4 \sqrt{g}$

Recommendations followed in Japan, Germany [21] or Poland [2] (1) are characterized by a greater safety margin (in terms of the nominal weld nugget diameter), yet at the cost of lower shear strength.

In terms of variant $\mathrm{M} 9$, shear strength was tested in relation to the non-overlap joint. The cross-sectional area of variant M9 amounted to $28.26 \mathrm{~mm}^{2}$ and was equal to the area of the weld nugget having a diameter of $6 \mathrm{~mm}$ (variant M1, i.e. the overlap joint). In the above-named case, the shear strength was by $16 \%$ higher than that related to variant M1.

Slightly higher (yet worth mentioning) shear force (by approximately $5 \%$ ) was obtained in the system of two welds in the serial arrangement in relation to the direction of shear force action (variant M6, Table 2, line 6). The foregoing resulted from the greater strength of the serial arrangement of welds subjected to tensile force.

The calculations concerning the shear force in variants M10 and M11 were performed in relation to the welding process (using the SORPAS ${ }^{\circledR}$ software programme). Following the welding process, (numerical) calculations concerning the shear test were performed automatically. In terms of the above-named variants, it was possible to observe an increase in shear force of approximately $41 \%$ and $35 \%$ in relation to high and low parameters respectively. The higher shear force resulted from the fact that the SORPAS ${ }^{\circledR}$ software calculated the weld nugget diameter (molten area) and the abovenamed parameter was compared with the reference value of variant M1. In turn, the higher shear force value related to the previously mentioned joint could be attributed to a greater joint area than the area of the molten material of the sheets, i.e. the weld nugget. The material outside the weld nugget was not molten but heated to high temperature and strongly plasticised. The zone outside the weld nugget formed an additional solid-state joint ring, which, once subjected to electrode force, could lead to an increase in the strength of the entire welded joint (Fig. 14).

Variants M10 and M11 demonstrated the difference of the value of shear force in relation to high and low welding parameters, which was connected with various values concerning the heat-affected zone and the indent left by the electrodes. The high and low parameters of the welding technology as well as measurement results linking the characteristic parameters are presented in Table 3 .

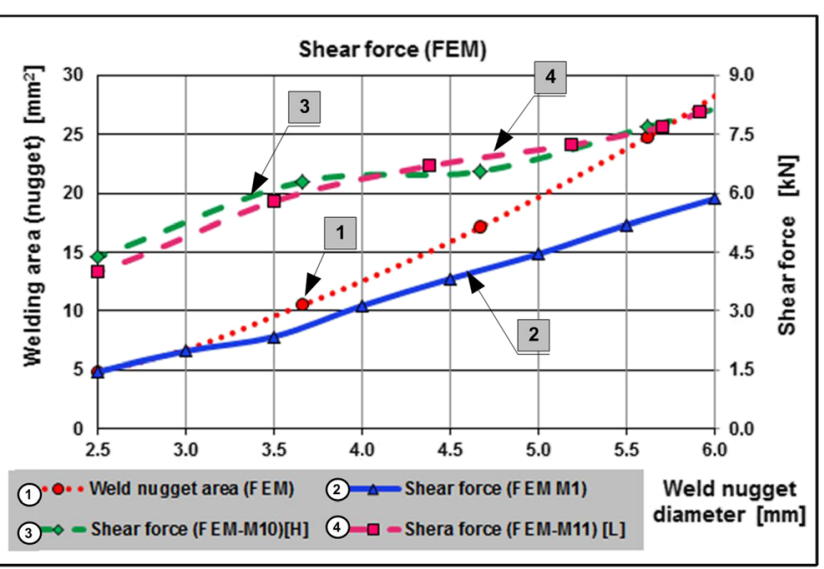

Fig. 12 Correlation between (1) weld nugget area (FEM), (2) shear force (FEM - variant M1), (3) shear force (FEM - variant M10), high parameters $[\mathrm{H}]$ and (4) shear force (FEM-variant M11), low parameters $[\mathrm{L}]$ in the function of the weld nugget diameter (FEM calculations-SORPAS®)

The analysed variants where the weld nugget shape was not circular (i.e. square and rectangular) did not reveal any significant increase in the maximum shear force (square weld nuggetvariant M3; rectangular weld nugget—variant M4). In turn, variant M5, i.e. the longitudinal rectangular weld nugget, revealed an increase in shear force of more than $6 \%$ (in comparison with variant M1). The increase in shear force observed in variant M5 could be ascribed to the weld elongation similar to that observed in variant M6. Further weld nugget elongation above $10.0 \mathrm{~mm}$, as was the case with variant M5, triggered a further increase in shear force. However, the technological welding tests revealed the necessity of using severalfold higher energy parameters (higher current and longer time), which triggered the discontinuation of further numerical analysis towards the elongation of the (rectangular) weld nugget. In the technological process, the fabrication of the circular weld was significantly easier than having the rectangular weld nugget. However, the foregoing does not determine the higher strength of the elongated weld nugget. An

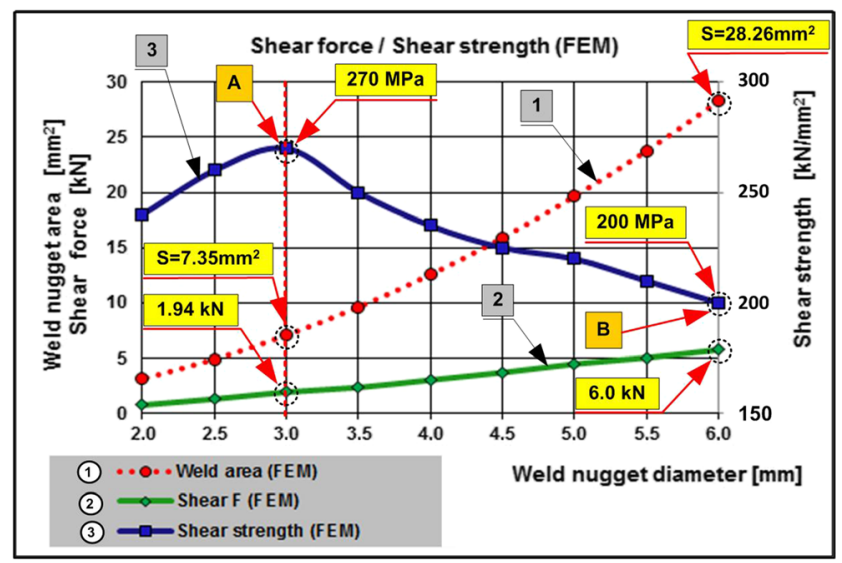

Fig. 13 Correlation between (1) weld nugget area (FEM), (2) shear force (FEM-M1) and (3) shear strength (FEM-M1) in the function of the weld nugget diameter (FEM calculations - SORPAS $®$, variant M1) 
Fig. 14 Analysed welded joints: (a) ideal weld (1) weld nugget and (3) base material; (b) welded joint: (1) molten material (weld nugget), (2) heat-affected zone and (3) base material

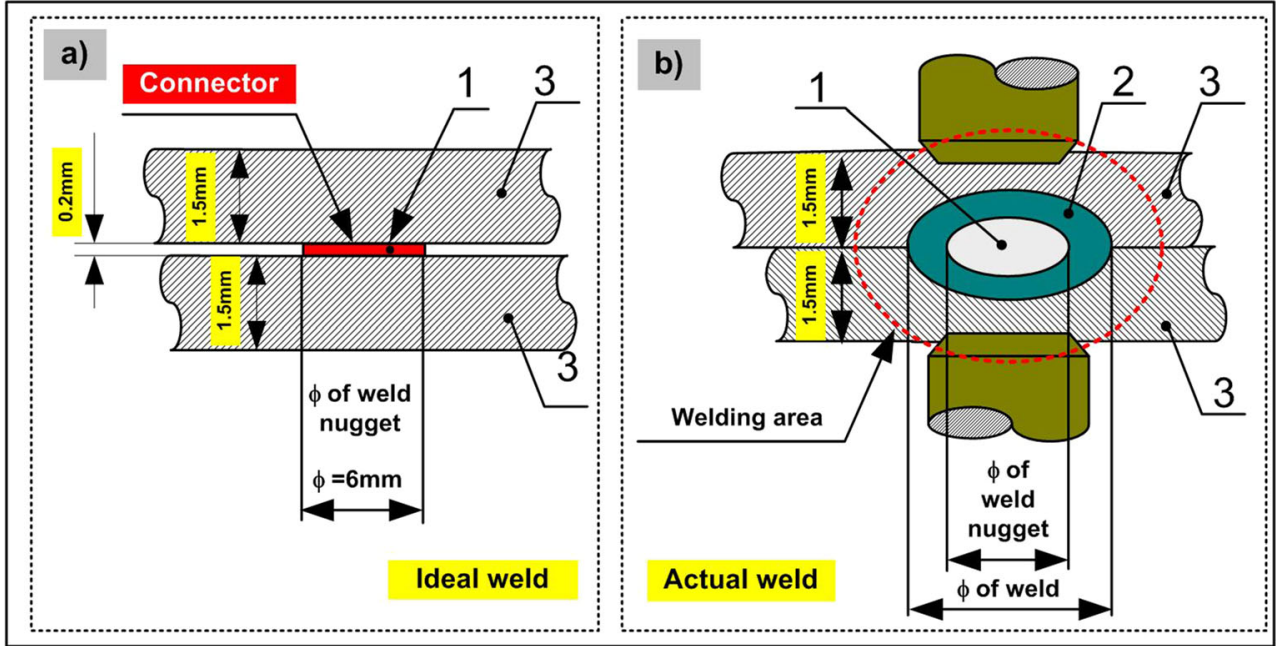

experimentally confirmed increase in tensile strength in relation to the increased length of the weld was reported in [22].

\subsection{Analysis of various weld nugget diameters}

An increase in the diameter of the weld nugget was accompanied by an increase in its area and, consequently, strength. Values of shear force in relation to the reference weld (variant M1, curve 2) and those of shear force in relation to the welds made using the FEM calculations (variant M10 and M11, curves 3 and 4) are presented in Fig. 12. The maximum shear force courses in relation to the ideal weld and the welds made using the FEM calculations were similar. It was possible to observe a correlation between an increase in shear force and an increase in the weld nugget diameter. However, the values of shear force were higher in relation to the computed weld (variant M10 and M11) than the ideal weld (variant M1) because of the greater joint area of the sheets (weld nugget and an additional solid-state joint) (Fig. 14).

The shear strength in relation to a nominal weld nugget diameter of $6 \mathrm{~mm}$ was $R_{\mathrm{t}}=200 \mathrm{MPa}$ (Fig. 13, item B). In turn, the highest shear strength $\left(R_{\mathrm{t}}=270 \mathrm{MPa}\right)$ indicated by the FEM calculations was related to the weld nugget having a diameter of $3.0 \mathrm{~mm}$ (Fig. 13, item A). The shear strength value related to the weld nugget having a diameter of $6 \mathrm{~mm}$ was by approximately $35 \%$ higher than that related to the weld nugget having a diameter of $3.0 \mathrm{~mm}$. The obtained results justified the conclusion that the most favourable dependence in terms of shear strength per a unitary weld nugget area was defined as follows (3):

$d=2.5 \sqrt{g}$

In relation to Eq. (3), the weld nugget area amounted to approximately $7.35 \mathrm{~mm}^{2}$. It was about 4 times smaller than the area of the weld nugget having a diameter of $6.0 \mathrm{~mm}(S=$ $28.26 \mathrm{~mm}^{2}$ ). It should be noted that the making of a set of welds composed of e.g. four welds having a diameter of $3.0 \mathrm{~mm}$ resulted in the same total area as that of the weld having a diameter of $6.0 \mathrm{~mm}$. However, in the above-named case, the total shear force of such a set was higher by $30 \%$ (for $4 \times \phi=3.0 \mathrm{~mm} F=1.95 \times$ $4=7.80 \mathrm{kN}$; for $1 \times \phi=6.0 \mathrm{~mm} F=6.0 \mathrm{kN}$ ). Shear force $F=$ $1.95 \mathrm{kN}$ was obtained in relation to the weld nugget having a diameter of $3.0 \mathrm{~mm}$ (Fig. 13).

\section{Results of experimental validation}

The size of the weld nugget (Fig. 14a) and of the weld (Fig. 14b) precluded the possibility of performing a direct comparison of results obtained in the numerical calculations with those obtained in the experiments. The performance of experimental tests aimed to verify the most important and testable aspects/factors affecting the value of shear force in relation to welded joints. The tests involved the making of a

Table 3 High/low welding parameters, characteristic parameters and FEM calculation results

\begin{tabular}{|c|c|c|c|c|c|c|c|c|}
\hline No. & $\begin{array}{l}\text { Welding } \\
\text { parameters }\end{array}$ & $\begin{array}{l}\text { Welding } \\
\text { current } \\
\mathrm{kA}\end{array}$ & $\begin{array}{l}\text { Welding time } \\
\text { (time of current flow) } \\
\text { ms }\end{array}$ & $\begin{array}{l}\text { Force } \\
\mathrm{kN}\end{array}$ & $\begin{array}{l}\text { Weld nugget } \\
\text { diameter } \\
\mathrm{mm}\end{array}$ & $\begin{array}{l}\text { Energy } \\
\mathrm{kJ}\end{array}$ & $\begin{array}{l}\text { Indent depth } \\
\mathrm{mm}\end{array}$ & $\begin{array}{l}\text { Shear force } \\
\mathrm{kN}\end{array}$ \\
\hline 1 & High & 10 & 160 & 3.0 & 6.0 & 2.0 & 0.13 & 8.46 \\
\hline 2 & Low & 7 & 410 & 1.5 & 6.0 & 2.8 & 0.10 & 8.10 \\
\hline
\end{tabular}




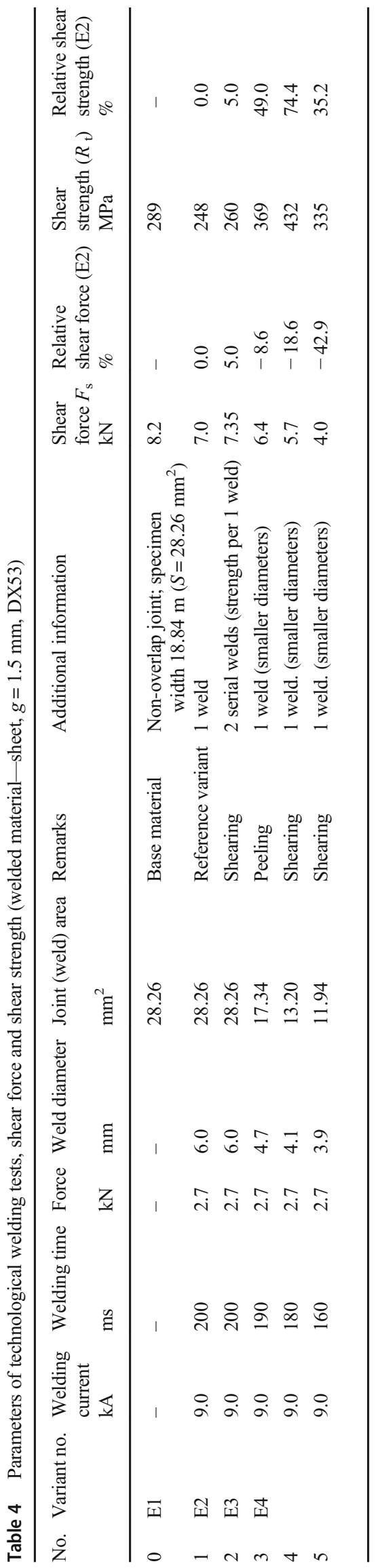

series of welds ( 50 welds) aimed to obtain the nominal weld nugget of $6 \mathrm{~mm}$ (Table 4, line 1). It was recognised as the experimental reference variant (E2) and compared with the remaining results of the experiments. The variants related to the technological welding tests presented in Table 4 are designated using the letter E (as in Experiment).

The shear tests performed within a static tensile test were performed in relation to:

1. Base material having the same cross-sectional area as the welded joint (Table 4, line 0 , variant E1),

2. Overlap joint - (one) weld having a diameter of $6.0 \mathrm{~mm}$ (Table 4 line 1, variant E2) as the reference weld,

3. Overlap joint-(two) welds having a diameter of $6.0 \mathrm{~mm}$ in the serial arrangement (distance between the welds amounted to $70 \mathrm{~mm}$ ) (Table 4 line 2, variant E3),

4. Overlap joints, in relation to one weld and increasingly shorter welding times, aimed to obtain the increasingly smaller diameter and the area of the weld (Table 4 lines $3,4$ and 5 , variant $\mathrm{E} 4)$.

The welded joints were subjected to peeling tests aimed to determine the weld diameter. The results are presented in Table 4. In turn, the correlation between the maximum shear force and the shear strength $\left(R_{\mathrm{t}}\right)$ is presented in Figs. 15 and 16 , respectively.

\section{Discussion on experimental test results}

The experimental tests confirmed the results obtained in the numerical calculations. When comparing the experimental test results concerning the reference weld (Table 4, line 1, variant E2) it was possible to observe:

1. Increase in shear force of approximately 5\% (variant E3) in relation to the two welds arranged in the serial system,

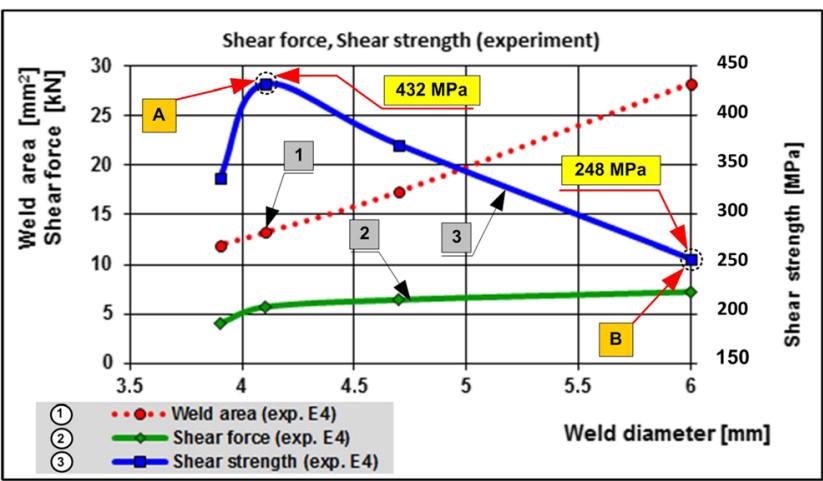

Fig. 15 Correlation between (1) weld area (experiment E4), (2) shear force (experiment E4) and (3) shear strength (experiment E4) in the technological welding test (experiment, variant E4) vs. the weld nugget diameter 


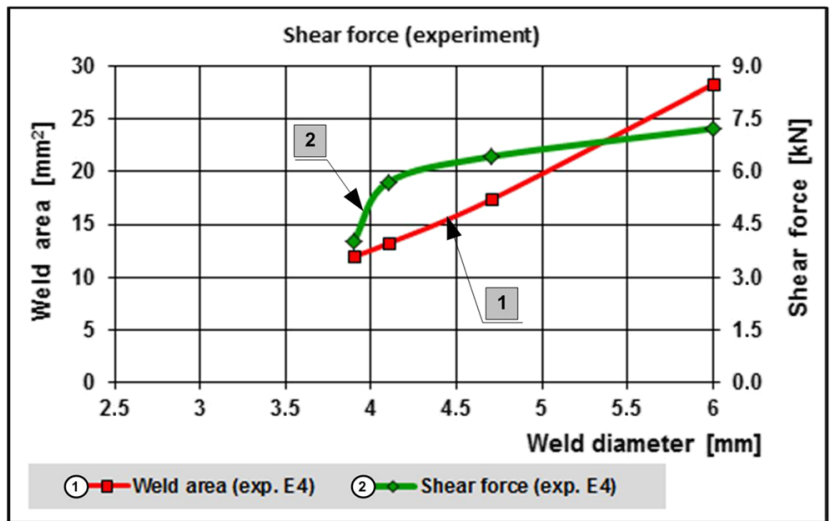

Fig. 16 Correlation between (1) weld nugget area (experiment - variant E4) and (2) shear force (experiment-variant E4) in the function of the weld nugget diameter

parallel to the direction of the shear force action; the diameter of each weld being $6.0 \mathrm{~mm}$;

2. Increase in shear strength $\left(R_{\mathrm{t}}\right)$, i.e. shear strength per the unitary weld area. The highest value obtained in the experimental tests in relation to a weld diameter of $4.1 \mathrm{~mm}$ (Table 4, line 4, variant E4). The highest value of shear strength was $R_{\mathrm{t}}=432 \mathrm{MPa}$ (Fig. 15, item A). In relation to $R_{\mathrm{t}}=248 \mathrm{MPa}$, corresponding to a weld diameter of $6.0 \mathrm{~mm}$ (Fig. 15, item B), the foregoing constituted an increase of approximately $74 \%$.

The graphical representation of the shear force $\left(F_{\mathrm{S}}\right)$ and the shear strength $\left(R_{\mathrm{t}}\right)$ of the weld under experimental conditions (Figs. 15 and 16) revealed similarity to the results obtained in the FEM calculations (Figs. 12 and 13).

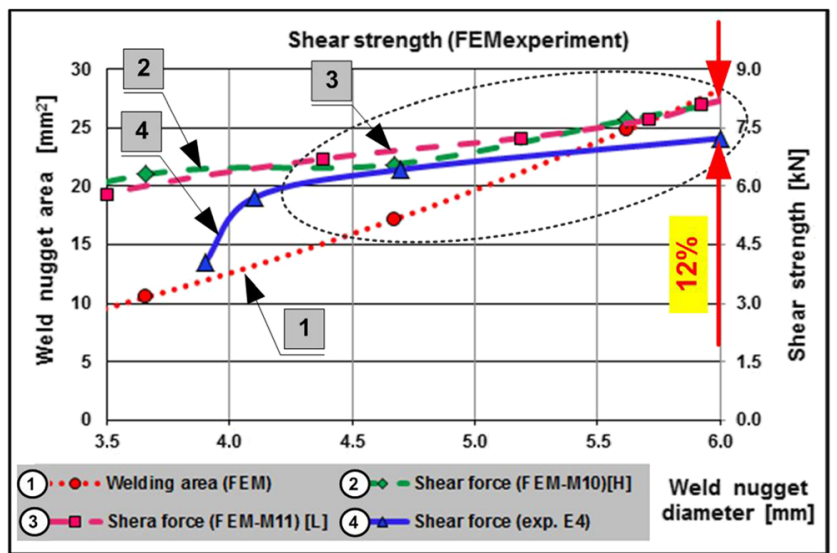

Fig. 17 Comparison of the shear strength obtained in the FEM calculations and in the experimental tests in relation to the weld nugget diameter: (1) weld nugget area (FEM), (2) shear strength, welding + shearing (FEM calculations, variant M10, high parameters [H]), (3) shear strength, welding + shearing (FEM calculations, variant M11, low parameters [L]) and (4) shear strength, technological welding test (experiment, variant $\mathrm{E} 4$ )

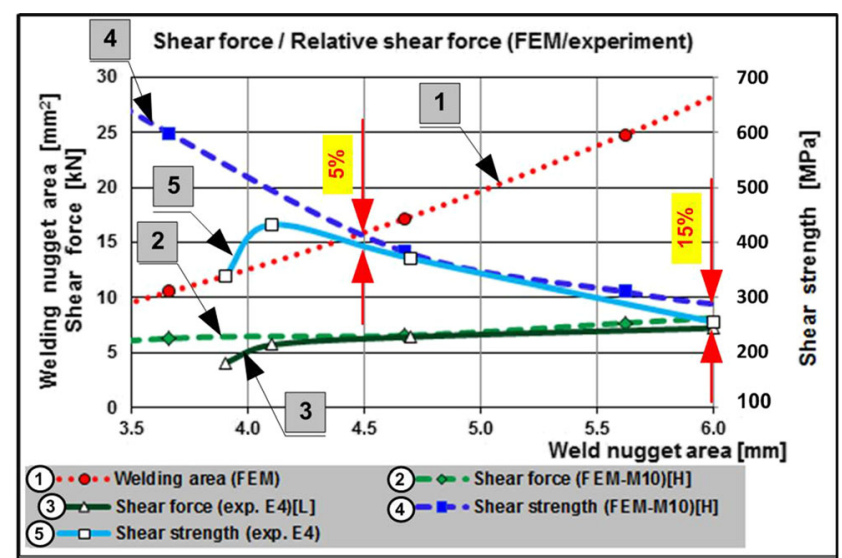

Fig. 18 Correlation between the shear force obtained in the FEM calculations and in the experimental tests in relation to the weld nugget diameter: (1) weld nugget area (FEM), (2) shear force, (FEM calculations, variant M10, high parameters $[\mathrm{H}]$ ), (3) shear force, (experiment, variant E4, high parameters $[\mathrm{H}]$ ), 4) shear strength, (FEM calculations, variant M10, high parameters $[\mathrm{H}]$ ) and (5) shear strength, (experiment, variant E4, high parameters $[\mathrm{H}]$ )

\section{Comparison of the results obtained in the FEM calculations and in the experimental tests}

The results obtained in the numerical calculations compared with those obtained in the experimental tests are presented in Figs. 17 and 18. It is possible to observe a significant correlation between the results obtained in the numerical calculations and those obtained in the experimental tests. When comparing the shear strength and adopting the experimental results as a reference, it was possible to notice (c.f. Fig. 17) that the numerical calculation results (within the weld nugget diameter range of 4.2 to $6.0 \mathrm{~mm}$ ) differed by approximately 10-12\% (weld nugget diameter $6 \mathrm{~mm}$, curve 4 as well as curves 2 and 3 ).

The analysed shear strength values (Fig. 18) in relation to the weld diameter range of 4.5 to $6.0 \mathrm{~mm}$ differed by a maximum of approximately $15 \%$ (curves 4 and 5).

\section{Concluding remarks}

The goal of the research-related tests discussed in the paper was accomplished. The research involved the examination of the effect of the weld nugget shape, the weld area and welding technology parameters on weld strength in the static tensile test based on numerical analysis (performed using the SORPAS ${ }^{\circledR}$ software) and laboratory tests. The results of the research work justified the formulation of the conclusions presented below.

- The experimental test results coincided with the numerical calculation results. Maximum differences between the 
FEM calculation results and the experimental test results of approximately $12 \%$ and $15 \%$ related to the maximum shear force and shear strength, respectively.

- Adopting the highest value of the shear strength in the static tensile test as the primary criterion, the most favourable variants were M8 and M6 (2 circular weld nuggets, $\phi=4.24-6.0 \mathrm{~mm})$. In the first case, shear strength increased in relation to two welds having a smaller weld nugget area and the total area equal to the reference weld area; the shear strength in relation to this joint was higher by $21 \%$ than that related to the reference variant.

- The results presented in the paper imply that the adopted criterion of the weld nugget diameter equal to five square roots of sheet thickness was not the most favourable. Bearing in mind the highest shear strength, it would be necessary to verify the selection criterion of the weld nugget diameter in relation to sheet thickness. As regards the above-presented aspect, the most favourable recommendations are those specified by the AWS (American Welding Society).

- Variant M6 revealed that the reduction of the angle between the weld plane and the direction of the tensile force action led to an increase in the shear strength of the joint. The angle became smaller when welds were arranged in series, in the direction of the tensile force action. In terms of variant M6 it was possible to observe an increase in tensile force of approximately $5 \%$. Very similar results, including an increase in shear force by $5 \%$, were obtained in the experiment.

- As expected, a significant increase in strength in relation to the weld having a non-circular nugget was not obtained. The square weld nugget (variant M3) was characterized by strength similar to that of the weld having the circular nugget (variant M1).

- In the rectangular weld nugget having the longer side parallel to the direction of the tensile strength action (also referred to as the longitudinal narrow weld nugget), it was possible to observe an increase in shear strength of more than 4\% (variant M5). Similar to variant M6, the above-named increase could be ascribed to the reduction of the angle between the weld plane and the direction of the tensile force action.

- The ideal weld-related tests also involved the analysis of the variant which was not an overlap joint. The sheet cross-sectional area was equal to the nominal weld area, whereas the shear force was higher by $16 \%$. However, the above-presented case was not applied in the overlap welding of sheets and was subjected to analysis only for comparative purposes.

- The calculations revealed that in the tensile test it was necessary to try and reduce the angle between the weld plane and the direction of shear force action. Positive results were observed in cases of (1) variant M5, i.e. the rectangular weld nugget - longer side parallel to the direction of the tensile force effect; and (2) variant M6, i.e. the serial system of welds in the direction of the tensile strength action.

- The calculations and laboratory tests performed to determine the numerical model of the ideal weld were considered mostly in terms of quality. The tendencies in the tests confirmed the functionality of the model proposed by the authors. Future work on the subject should be focused on the detailed determination of the properties of ideal weld numerical model, including an aspect related to the accuracy of results.

Open Access This article is licensed under a Creative Commons Attribution 4.0 International License, which permits use, sharing, adaptation, distribution and reproduction in any medium or format, as long as you give appropriate credit to the original author(s) and the source, provide a link to the Creative Commons licence, and indicate if changes were made. The images or other third party material in this article are included in the article's Creative Commons licence, unless indicated otherwise in a credit line to the material. If material is not included in the article's Creative Commons licence and your intended use is not permitted by statutory regulation or exceeds the permitted use, you will need to obtain permission directly from the copyright holder. To view a copy of this licence, visit http://creativecommons.org/licenses/by/4.0/.

\section{References}

1. PN-EN ISO 14273:2016-05, Welding - Destructive testing of welds - Dimensions of the sample and test procedure for shear of welded resistance and spot welded joints

2. Papkala H (2003) Resistance welding of metals (in polish). KaBe, Krosno

3. Zhang H, Senkara J (2011) Resistance welding fundamentals and applications. Taylor\&Francis Group, Abingdon

4. Bračun D., Polajnar I., Diaci J.: Application of Contemporary NonDestructive Testing in Engineering. Indentation shape parameters as indicators of spot weld quality. The $8^{\text {th }}$ International Conference of the Slovenian Society for Non-Destructive Testing, September 13, 2005, Portorož, Slovenia, pp 419-427

5. Robert W. Messler Jr, 1999, Principles of welding: processes. Physics, Chemistry, and Metallurgy

6. Nielsen C.V., Zhang W., Alves L.M. Bay N., Martins P.A.F., 2013, Modelling of thermo-electro-mechanical manufacturing processes applications in metal forming and resistance welding, Springer Briefs in Applied Sciences and Technology

7. Na T-H, Na S-J, Park Y-W (2018) A study on characteristics of end plug resistance welding process, in nuclear fuel rods by experiment and numerical simulation. Int J Adv Manuf Technol 98:2241-2255. https://doi.org/10.1007/s00170-018-2365-3

8. Ren D, Zhao D, Liu L, Zhao K (2019) Clinch-resistance spot welding of galvanized mild steel to $5083 \mathrm{Al}$ alloy. Int J Adv Manuf Technol 101:511-521. https://doi.org/10.1007/s00170018-2854-4

9. Karimi MR, Sedighi M, Afshari D (2015) Spot welding process of aluminum alloy 6061-T6. Int J Adv Manuf Technol 77:885-895. https://doi.org/10.1007/s00170-014-6492-1

10. Hassan Rezayat, S. S. Babu, Hassan Ghassemi-Armaki (2016) Effects of heat affected zone softening extent on strength of 
advance high strength steels resistance spot weld, Proceedings of the $10^{\text {th }}$ International Conference Tokyo, Japan

11. Ashiri R, Marashi SPH, Park Y-D (2018) Weld Processing and Mechanical Responses of 1-GPa TRIP Steel Resistance Spot Welds. Weld Int:157-169. https://doi.org/10.29391/2018.97.014

12. Song Q (2003) Testing and modeling of contact problems in resistance welding, Doctoral Thesis, Technical University of Denmark

13. Portilho LT, de Oliveira Nogueira LR, de Castro JA (2015) Evaluation of resistance welding procedures suitable for the SAE 1008 wire rods assisted by $\mathrm{DoE}$ technique, 23rd ABCM International Congress of Mechanical Engineering, Rio de Janeiro, Brazil. https://doi.org/10.20906/CPS/COB-2015-2319

14. Raut M, Achwal V (2014) Optimization of spot welding process parameters for maximum tensile strength. Int. J. Mech. Eng. \& Rob. Res 3(4)

15. Chaudhary K (2017) A comparative study of arc welding and resistance welding processes. Journal of Emerging Technologies and Innovative Research (JETIR) 4(11)

16. Mikno Z, Grzesik B 2018 The strength of the resistance weld with respect to its geometry, Intermediate Meeting Commission IIIA, IIW (International Institute of Welding), Paris, document no. III1862-18
17. The database of the material and electrode parameters: model 2D version 11.2 and model 3D Version 4.0x64 of the Swantec Inc. SORPAS® Software. http://swantec.com/. Accessed 15 Apr 2020

18. User Manual SORPAS® 3D Version 4.0 x64 (2015) SWANTEC Software and Eng. ApS

19. Engineer's Guide (2005) Welding (in polish) vol. 2, WNT Warszawa

20. 2003 Resistance Welding Manual 4th edition. RWMA, Section 1, Processes, Spot Welding

21. Yang Y-P, Gould J., 2016, Recent advances in predicting resistance spot-weld failure for automotive structure performance modelling. 9th International Seminar \& Conference on Advances in Resistance Welding, April 12-15, 2016, Miami

22. Yang H, Zhang Y, Lai X, Chen G (2008) An experimental investigation on critical specimen sizes of high strength steels DP600 in resistance spot welding. Mater Des 29:1679-1684

Publisher's note Springer Nature remains neutral with regard to jurisdictional claims in published maps and institutional affiliations. 